\title{
CALCULATION OF OPTIMAL SIZES OF REFLECTING ELEMENTS OF THE MOSAIC CONCENTRATOR
}

\author{
Kuchkarov Akmaljon Axmadaliyevich \\ PhD. Associate Professor, Department of Information technology, Ferghana Polytechnic Institute, \\ Ferghana, Uzbekistan
}

\author{
Muminov Shermuhammad Abdushukur ugli \\ Assistant, Department of Information technology, Ferghana Polytechnic \\ Institute, Ferghana, Uzbekistan
}

Egamberiyev Xomidjon Abdullayevich

Assistant, Department of Information technology, Ferghana Polytechnic Institute, Ferghana, Uzbekistan

Article DOI: https://doi.org/10.36713/epra4561

\begin{abstract}
ANNOTATION
The article deals with the main relations of choosing the optimal sizes of mosaic concentrator elements, as well as large- sized faceted elements on a paraboloid and mosaic basis, taking into account the optimal size of the scattering spot (receiver) at the maximum efficiency value obtained for the power generating station.
\end{abstract}

KEYWORDS: parabola, mosaic, focus, facet and concentrator, receiver.

\section{INTRODUCTION}

Currently, in solar thermal power stations (SES) of high power, two schemes of concentration of solar radiation are used. The first, "point" focusing (tower SES) and the second, "linearly" focusing with linear concentrators (LC) - Luz SES [1]. Concentrators of solar radiation are optical systems (mirror, lens, or mixed mirror-lens) that change the course of the sun's rays (by reflection or refraction) so that they reach a certain radiation receiver. In the general case, two optical schemes for the concentration of solar radiation can be distinguished: single-mirror (single-lens) and multi-mirror (multi-lens). The former include, for example, cylindrical with various second-order curves in the section, spherical, parabolic, etc. [2].

The production of solid parabolic and mosaic mirrors is associated with great technological difficulties, so it is more economical to produce powerful energy concentrators from separate reflecting elements [3-5]. One of the variants of this type is mosaic concentrators, the individual elements of which have a flat surface [6-7]. Having an approximate parabolic and mosaic surface made in one way or another during the process of gluing flat elements to the surface of the concentrator, adjusting these elements, you can achieve a good quality of the focal spot [8-9].

\section{MATERIAL AND METHODS}

Using a theoretically accurate paraboloid and a mosaic of rotation of a certain diameter and focal length, we will try to solve the following problem. A separate mirror of a certain size is installed relative to this parabolic and mosaic surface. Find the dependence of the element size (flat mirror) on the size (diameter) of the 


\section{EPRA International Journal of Research and Development (IJRD) \\ Volume: 5 | Issue: 5 | May 2020 \\ - Peer Reviewed Journal}

focal spot. In this case, let us consider the case when rays fall on a parabolic surface that are parallel to the optical axis of the paraboloid by rotations of the focal zone has a flat shape [10].

The angle between the optical axis and the tangent to the paraboloid has different values for different points on the parabolic surface, and the smallest value is obtained for the most extreme point. This means that from the mirror installed at this point, a beam of rays will go most deflected to the optical axis, and these rays, cut by the focal plane, will give the largest size of the spot.

\section{DISCUSSION RESULTS}

Therefore, if the dimensions of the mirrors are the same, we will make calculations for the extreme mirror. The angle $\mathbf{2} \mathbf{U}$ and the angle between the incident beam and the normal to the reflecting surface $\boldsymbol{\alpha}$ are connected, i.e.

$$
U=2 \alpha .
$$

From $\triangle \mathrm{ABC}$ and $\triangle \mathrm{MKE}$ we have:

$$
\begin{aligned}
& b=l \cos \alpha \\
& b=d^{\prime} \cos U
\end{aligned}
$$

Hence, given (1), we get

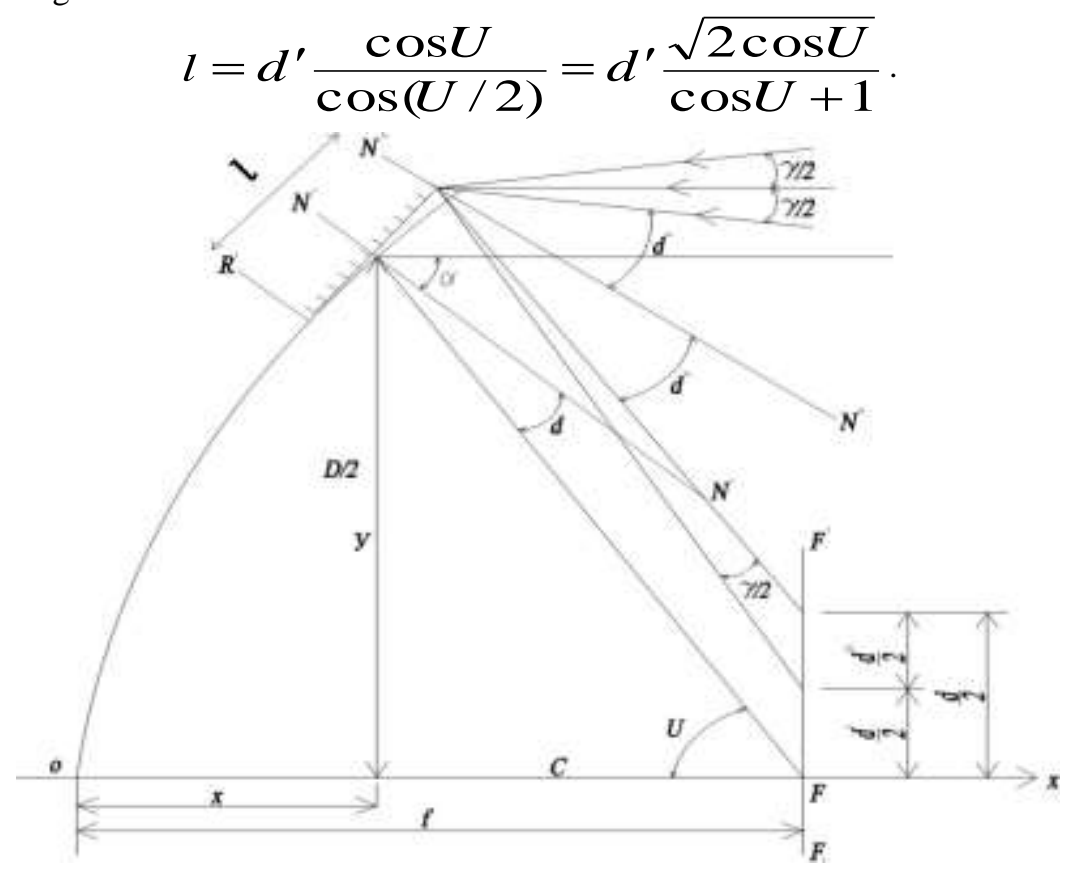

Figure 1.To calculate the dependence of the size of the element $l$ on the $f$ and $D$ of the concentrator, taking into account the angular size of the Sun.

The the following expressions can be written (Figure 1):

$$
\begin{aligned}
& R F=x+f \\
& C=f-x \\
& C=R F \cos U \\
& C=(f+x) \cos U \\
& \cos U=\frac{f-x}{f+x}
\end{aligned}
$$




$$
\begin{array}{r}
\text { Considering } x=\frac{2 Y}{16 f}, \\
\text { we get } \cos U=\frac{16 f^{2}-2 Y^{2}}{16 f^{2}+2 Y^{2}} .
\end{array}
$$

Substituting the cos U value in expressions (4), we define

$$
l=d^{\prime} \frac{16 f^{2}-2 Y^{2}}{4 f \sqrt{16 f^{2}+2 Y^{2}}} .
$$

Consider the actual condition of the concentrator, that is, when a beam of rays coming from the Sun falls on it. We take into account that the angular size of the Sun, $\Delta \gamma=322^{\prime}=0.0093$ radian, f- focal length, Ffocal plane. meaning:

The dependence of the diameter of the focal spot on the angular size of the Sun has the following

$$
d^{\prime \prime} \approx f t g \gamma
$$

In a first approximation, it can be assumed that the rays from the extreme mirror determine the additional increase, i.e., the actual diameter of the focal spot, taking into account the angular size of the Sun from a separate plane mirror, installed with respect to the mosaic, parabolic and parabolic cylindrical surface, is

$$
\mathrm{d}=\mathrm{d}^{\prime}+\mathrm{d}^{\prime \prime} \text {. }
$$

Substituting the values of $d$ 'into expressions (4) and (12), we can obtain

$$
\begin{gathered}
l \approx(d-f t g \gamma) \frac{16 f^{2}-2 Y^{2}}{4 f \sqrt{16 f^{2}+2 Y^{2}}} \\
l \approx(d-f t g \gamma) \frac{\cos U}{\cos (U / 2)}
\end{gathered}
$$

Thermal solar systems in practice, the most beneficial is the opening angle $2 \mathrm{U}=90^{\circ}$. Then, given

$$
\begin{aligned}
& \qquad f=\frac{2 Y}{4} \operatorname{ctg} \frac{U}{2} \\
& \text { Can find } l \approx 0,5774 d-0,0054 f, \\
& \text { or } l \approx 0,5774 d-0,0023 * 2 Y f, \\
& \text { or } l \approx 1,7320 l+0,0093 f, \\
& \text { or } l \approx 1,7320 l-0,0040 * 2 Y,
\end{aligned}
$$

We establish the relationship between the size of the element, the diameter of the concentrator and the concentration coefficient. From the expression (16) it follows:

$$
l \approx\left(d-\frac{2 Y}{4} \operatorname{ctg} \frac{U}{2} \operatorname{tg} \gamma\right) \frac{\cos U}{\cos (U / 2)} .
$$




\section{EPRA International Journal of Research and Development (IJRD)}

From here $\frac{l}{d}=\frac{d}{2 Y} \frac{\cos U}{\cos (U / 2)}-\frac{\cos U}{4 \sin U / 2} \operatorname{tg} \gamma$.

Because $\left(\frac{2 Y}{d}\right)^{2}=K_{g}$

where, concentration coefficient,

Dependence of the concentrator diameter (D) on the size of the elements $(l)$.

Table 1

\begin{tabular}{|c|c|c|c|c|c|c|c|c|}
\hline \multirow{2}{*}{$\mathbf{D}, \mathbf{m}$} & \multicolumn{10}{|c|}{$\mathbf{K}_{\mathbf{g}}$ values } \\
\cline { 2 - 9 } & 100 & 200 & 400 & 600 & 800 & 1000 & 1200 & 1400 \\
\hline 0,5 & 27,7 & 19,3 & 13,3 & 10,7 & 9,1 & 8 & 7,2 & 6,6 \\
\hline 1,0 & 55,4 & 38,5 & 26,6 & 21,3 & 18,1 & 16 & 14,4 & 13,1 \\
\hline 1,50 & 83,1 & 57,8 & 39,9 & 32 & 27,2 & 24 & 21,8 & 19,7 \\
\hline 2,0 & 110,8 & 77 & 53,2 & 42,6 & 36,2 & 32 & 28,8 & 26,2 \\
\hline 2,50 & 138,5 & 96,3 & 66,5 & 53,3 & 45,3 & 40 & 36 & 32,8 \\
\hline 3,00 & 166,2 & 115,5 & 79,8 & 63,9 & 54,3 & 48 & 43,2 & 39,3 \\
\hline 3,50 & 193,9 & 134,8 & 93,1 & 74,6 & 63,4 & 56 & 50,4 & 45,9 \\
\hline 4,00 & 221,6 & 154 & 106,4 & 85,2 & 72,4 & 64 & 57,6 & 52,4 \\
\hline 4,50 & 249,3 & 173,3 & 119,7 & 95,9 & 81,5 & 72 & 64,8 & 59 \\
\hline 5,00 & 277 & 192,5 & 133 & 106,5 & 90,5 & 80 & 72 & 65,5 \\
\hline 6,00 & 332,4 & 231 & 159,6 & 127,8 & 108,6 & 96 & 86,4 & 78,6 \\
\hline 7,00 & 387,8 & 269,5 & 186,2 & 149,1 & 126,7 & 112 & 100,8 & 91,7 \\
\hline 8,00 & 443,2 & 308 & 212,8 & 170,4 & 144,8 & 128 & 115,2 & 104,8 \\
\hline 9,00 & 498,6 & 346,5 & 239,4 & 191,7 & 162,9 & 144 & 129,6 & 117,9 \\
\hline 10,00 & 554 & 385 & 266 & 213 & 181 & 160 & 144 & 131 \\
\hline
\end{tabular}

$$
\begin{array}{r}
l \approx\left(\frac{1}{\sqrt{K_{g}}} \frac{\cos U}{\cos U / 2}-\frac{\cos U}{4 \sin U / 2} \operatorname{tg} \gamma\right) 2 Y \\
\text { at, } 2 U=120^{0}, l \approx\left(\frac{1}{\sqrt{3 K_{g}}}-0,0023\right) 2 Y
\end{array}
$$

\section{CONCLUSIONS}

1. The dependence of the size of the element (flat mirror) on the size (diameter) of the focal spot for concentrating systems with parabolic and mosaic mirrors for the case of the flat shape of the focal zone has been revealed.

2. A method of calculating the dimensions of individual reflecting elements of a mosaic concentrator with a rigid parabolic surface has been developed.

\section{FUNDING}

This work was carried out in the framework of the state program of the Ministry of Innovative Development of the Republic of Uzbekistan under the OT-F-3-19 applied research project of the Fergana Polytechnic Institute. 


\section{EPRA International Journal of Research and Development (IJRD) \\ Volume: 5 | Issue: 5 | May 2020 \\ - Peer Reviewed Journal}

\section{ACKNOWLEDGMENTS}

The authors are grateful to the heads of the laboratory of the "Big Solar Installation", Doctor of Technical Sciences, Professor A.A. Abdurakhmanov.

\section{REFERENCES}

1. Hank Price, Eckhard Lupfert, David Kearney, Eduardo Zarza, Gilbert Cohen, Randy Gee, Rod Mahoney. Advances in Parabolic Trough Solar Power Technology, J. Sol. Energy Eng. May 2002, Vol.124, №2, pp. 109125.

2. R. Winston, J.C. Minano and P. Benitez, "Nonimaging Optics”, Elsevier Academic Press, pp. 1-217, (2005).

3. Zakhidov R.A. Technology and Testing of Solar Energy Concentrating Systems // (English Edition) Gujarat Energy Development Agency Vadodara. 1996. -P.184.

4. Abdurakhmanov A.A. Mirror-concentrating systems of solar power and process plants and their efficiency when using receivers of selective radiation absorption: Dis. Doctor of Engineering Sciences. - M: 1992. 300 pages.

5. Klychev S.I. Modeling of receiving and concentrating devices of solar thermal power plants: Dis. Doctor of Engineering Sciences-T. FTI. 2004. 268 pages.

6. Kuchkarov A.A., Abdurakhmanov A. Calculation of optimal dimensions of reflecting elements of mosaic concentrator//Materials of the Respubli Scientific and Technical Conference "Modern Problems of Renewable Energy" May 18-19, 2018, Karshi, C.67-71.

7. Kuchkarov A.A., Kholova Sh. R., Abdumuminov A. A., Abdurakhmanov A. Optical energy characteristics of the optimal module of a solar composite parabolic-cylindrical plant. Applied Solar Energy.-New York, 2018, Vol. 54, №. 4, pp. 293-296.

8. Akbarov R.Yu., Kuchkarov A.A. Modeling and Calculation of Optical-Geometric Characteristics of a Solar Concentrator with Flat Fresnel Mirrors // Applied Solar Energy.-New York, 2018, Vol. 54, No. 3, pp. 187-192.

9. Abdurakhmanov A.A., Axadov J.Z., Mamatkosimov M.A., Klychev Sh.I. Kontsentriruyushchie sistemy $i$ vybor optimalnyx parametrov luchevos-prinimayushchey poverxnosti // Geliotexnika. 2009. №2. - S.72-76

10. Kuchkarov A.A., Holov Sh.R., Abdumuminov A.A., Abdurakhmanov A. Calculation of optical-geometrical characteristics of parabolic-cylindrical mirror concentrating systems. "European science review" \# 1-2, 2017, pp.28-32. 